\title{
Effect of microplastics on aquatic biota: A hormetic perspective ${ }^{\text {th }}$
}

\author{
Tao Sun ${ }^{\text {a,d }}$, Junfei Zhan ${ }^{\text {a,d }}$, Fei Li ${ }^{\text {a,c }}$, Chenglong Ji ${ }^{\text {a,b,c }}$, Huifeng $\mathrm{Wu}^{\text {a,b,c, * }}$ \\ ${ }^{\text {a }}$ CAS Key Laboratory of Coastal Environmental Processes and Ecological Remediation, Yantai Institute of Coastal Zone Research (YIC), Chinese Academy of Sciences \\ (CAS); Shandong Key Laboratory of Coastal Environmental Processes, YICCAS, Yantai, 264003, PR China \\ ${ }^{\mathrm{b}}$ Laboratory for Marine Fisheries Science and Food Production Processes, Qingdao National Laboratory for Marine Science and Technology, Qingdao, 266237, PR China \\ ${ }^{\mathrm{c}}$ Center for Ocean Mega-Science, Chinese Academy of Sciences (CAS), Qingdao, 266071, PR China \\ ${ }^{\mathrm{d}}$ University of Chinese Academy of Sciences, Beijing, 100049, PR China
}

\section{A R T I C L E I N F O}

\section{Keywords:}

Plastic pollution

Aquatic environment

Dose response

Risk assessment

Environmentally relevant concentrations

\begin{abstract}
A B S T R A C T
As emerging pollutants, microplastics (MPs) have been found globally in various freshwater and marine matrices. This study recompiled 270 endpoints of 3765 individuals from 43 publications, reporting the onset of enhanced biological performance and reduced oxidative stress biomarkers induced by MPs in aquatic organisms at environmentally relevant concentrations ( $\leq 1 \mathrm{mg} / \mathrm{L}$, median $=0.1 \mathrm{mg} / \mathrm{L}$ ). The stimulatory responses of consumption, growth, reproduction and survival ranged from $131 \%$ to $144 \%$ of the control, with a combined response of $136 \%$. The overall inhibitory response of 9 oxidative stress biomarkers was $71 \%$ of the control, and commonly below $75 \%$. The random-effects meta-regression indicated that the extents of MPs-induced responses were independent of habitat, MP composition, morphology, particle size and exposure duration. The results implied that the exposure to MPs at low and high concentrations might induce opposite/non-monotonic responses in aquatic biota. Correspondingly, the hormetic dose response relationships were found at various endpoints, such as reproduction, genotoxicity, immunotoxicity, neurotoxicity and behavioral alteration. Hormesis offers a novel perspective for understanding the dose response mode of aquatic organisms exposed to low and high concentrations of MPs, highlighting the necessity to incorporate the hormetic dose response model into the ecological/ environmental risk assessment of MPs.
\end{abstract}

\section{Introduction}

Plastics products are ubiquitous in our daily life due to their lightweight, inexpensive and durable properties (Pahl et al., 2017). Over the past 70 years, global plastic production has increased exponentially from 5 million tons annually in the 1950s (Thompson, 2015) to over 350 million tons today (PlasticsEurope, 2020). If the current trend continues, the global plastic production is expected to reach 1.1 billion tons in 2050 (Geyer, 2020), leading to an extra 33 billion tons of plastic (Rochman et al., 2013). With high volume manufacturing, intensive use and slow degradation, plastic debris are observed in almost all habitats (Bouwmeester et al., 2015). As an important sink, the aquatic environment is continuously accumulating massive plastic waste (Jambeck et al., 2015; MacArthur, 2017). Nowadays, plastic-caused entanglement, ingestion and potential toxicity pose a serious threat to the health of aquatic biota (Ostle et al., 2019).
Tiny plastic (less than $5 \mathrm{~mm}$ in diameter) termed microplastic (MP) is the predominant form of plastic debris in aquatic environments (Galloway et al., 2017). The occurrence of MPs involves both primary (e. g. cosmetic products and synthetic textiles) and secondary sources (mainly the fragmentation of larger plastic debris) (Cole et al., 2011). With small size, large surface and strong hydrophobicity, MPs are easily ingested by aquatic organisms, accumulated in tissues and transferred in food webs (Setälä et al., 2014; Kane et al., 2020). Additionally, MPs can adsorb persistent organic pollutants and trace metals, act as vectors and release these hazardous substances into aquatic environments, causing more damages than large plastics (Brennecke et al., 2016; Wang et al., 2018). As emerging contaminants in aquatic environments, MPs attract considerable public and scientific attention (Fig. 1a), and become a global environmental concern (Burns and Boxall, 2018; de Souza Machado et al., 2018; Klingelhöfer et al., 2020).

Hormesis is a central toxicological concept to account for mild stress-

\footnotetext{
This paper has been recommended for acceptance by Baoshan Xing.

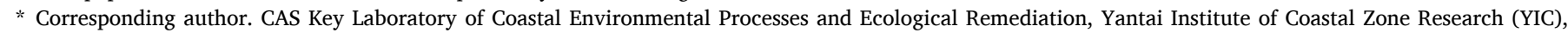
Chinese Academy of Sciences (CAS); Shandong Key Laboratory of Coastal Environmental Processes, YICCAS, Yantai, 264003, PR China.

E-mail address: hfwu@yic.ac.cn (H. Wu).
} 
$\mathbf{a}$

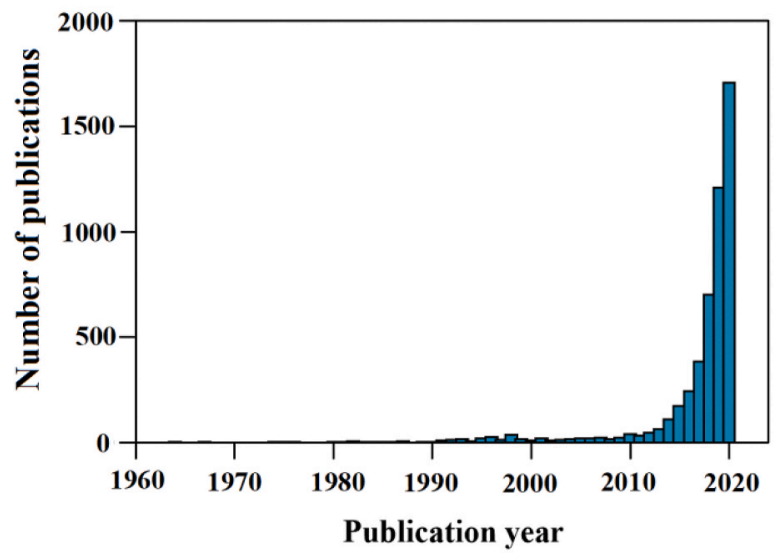

b

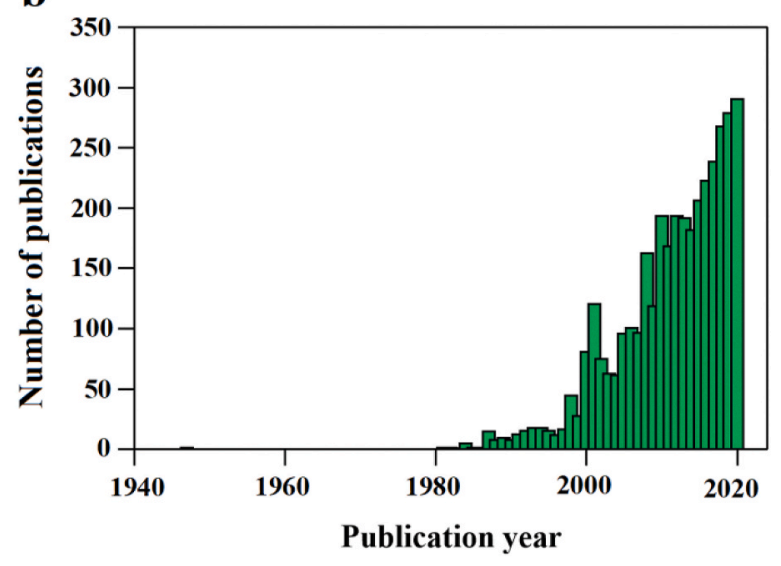

Fig. 1. Number of publications about microplastics (MPs) (a) and hormesis (b).

induced beneficial effect (Calabrese and Blain, 2011). The concept of hormesis assumes that low dose of stressor agent can induce an adaptive response and strengthen the biological performance, while high dose may cause an adverse response and weaken the biological resilience (Mattson, 2008; Rattan et al., 2009; Calabrese, 2013; Le Bourg, 2019). This can be displayed in a biphasic dose response relationship. The hormetic effect can be triggered by low to moderate toxicity induction or by overcompensation for homeostasis disruption, which can not only rapidly repair damage and reset the homeostatic setpoint, but also act as a preconditioning stimulus to protect the organism from more serious challenges (Calabrese et al., 2016). Recently, the phenomenon of hormesis has been increasingly documented in publications (Fig. 1b), and the hormetic model has been gradually developed into a fundamental dose response model in toxicology (Calabrese et al., 2016; Costantini and Borremans, 2019).

The potential toxicity of MPs to aquatic organisms is one of the hotspots in global environmental research (Wright et al., 2013; Anderson et al., 2016; de Sá et al., 2018; Franzellitti et al., 2019; Ma et al., 2020). The concentration of MPs in natural aquatic environments is very low (typically below $1 \mathrm{mg} / \mathrm{L}$ ) (Chen et al., 2020a). However, some negative effects of MPs on aquatic organisms were observed through environmentally unrealistic concentrations (generally 2 to 7 orders of magnitude of the environmental level), which may lead to overreaction or misunderstanding of the risk of MPs (Lenz et al., 2016; Burns and Boxall, 2018; Revel et al., 2020). It is of great significance to evaluate the effect of MPs in aquatic organisms at environmentally relevant concentrations (de Sá et al., 2018). Therefore, this study was conducted, aiming to (i) recompile the data of enhanced biological performance and reduced oxidative stress biomarkers in aquatic biota induced by MPs at environmentally relevant concentrations; (ii) evaluate the characteristics of MPs-induced stimulatory and inhibitory responses; (iii) provide evidence for MPs-induced hormetic dose response relationships. In order to achieve these goals, a systematic literature search was conducted, followed by data extraction and meta-analysis for data integration, and subsequently meta-regression was used to assess the changes in extents of the stimulatory/inhibitory responses.

\section{Materials and methods}

\subsection{Literature retrieval}

In order to extensively collect the literature on the toxicity of MPs to aquatic organisms, referring to the Cochrane handbook v.6.1 (Higgins et al., 2020), three databases including Web of Science Core Collection, Medline and the Cochrane Library were systematically searched using the terms and modifiers: "plastic, debris, exposure, toxic*, effect, aquatic, organism, biota, wildlife, environment, freshwater, marine, sea, ocean, horme*, dose response, dose-response, biphasic response, acclimation response, adaptive response, preconditioning, conditioning, stimulation, stimulatory, inhibition, inhibitory, without language restriction. Grey literature (e.g. conference papers and dissertations) were also searched via Index to Scientific and Technical Proceedings and Baidu Scholar. The initial literature search was conducted in July 2020, and supplementary collections were performed in October 2020 and March 2021.

\subsection{Inclusion criteria}

The titles, abstracts, keywords and full-texts of all retrieved publications (2952 in total) were screened by two researchers for considering inclusion according to the following criteria: (i) original research paper reported the effect of MPs on consumption (e.g. egestion amount, ingestion rate), growth (e.g. body length, change in weight), reproduction (e.g. hatching rate, number of offspring), survival (e.g. mortality rate, survival time), or oxidative stress biomarker (e.g. lipid peroxidation, reactive oxygen species) (Foley et al., 2018; Prokić et al., 2019); (ii) designed at least one control group and one stimulatory/inhibitory group; (iii) the stimulatory/inhibitory response was defined as a difference of $10 \%$ or more from the control, also corresponding to the diagnostic threshold among multiple medical/toxicological studies (e.g. Wiesenack et al. (2005), Laffosse et al. (2011), Biais et al. (2017) and Trucco et al. (2018)), or less than $10 \%$, but there was a statistical difference; (iv) the exposure concentration threshold of MPs was set at 1 $\mathrm{mg} / \mathrm{L}$ (see the review of Yu et al. (2020)) that could cover/overlap/be at the same order of magnitude as the maximum concentrations found in multiple natural environments (e.g. $0.94 \mathrm{mg} / \mathrm{L}$ in Amsterdam canals, the Netherlands (Leslie et al., 2017), 1.01 mg/L in Geoje Island, South Korea (Song et al., 2014), $0.62 \mathrm{mg} / \mathrm{L}$ in Colombian Caribbean, Colombia (Garcés-Ordóñez et al., 2020), and $1.26 \mathrm{mg} / \mathrm{L}$ in Saigon River, Vietnam (Strady et al., 2020), estimated by trawling depth of $0.1 \mathrm{~m}$ and/or an average weight of $5 \mu \mathrm{g}$ /particle proposed by Besseling et al. (2019) where needed) and used in environmentally relevant studies (e.g. O'Donovan et al. (2018), Chen et al. (2020a) and Teng et al. (2021)); (v) the response was induced by MPs only (i.e. not combined exposure with organic pollutants/trace metals); (vi) the mean with standard error (SE) or standard deviation $(S D)$ of each endpoint could be obtained directly or calculated indirectly.

\subsection{Data extraction}

The following information were extracted from included literature: (i) the first author; (ii) publication year; (iii) freshwater or marine habitat; (iv) the sample size, mean and SD/SE; (v) the mean size, 
morphology and composition of MPs; (vi) exposure concentration and duration. Data were extracted directly from tables and full-texts. However, if data were displayed graphically, the Getdata Graph Digitizer v.2.24 software (http://getdata-graph-digitizer.com/) was used to measure the values (Sahebkar et al., 2015; Mazidi et al., 2017; Yang et al., 2020). During the data extraction process, any discrepancies between two researchers were resolved by discussion or consultation with the third researcher.

\subsection{Data analysis}

For the endpoint classified as biological performance indicators (i.e. consumption, growth, reproduction, survival), if an increased response indicating a positive effect (e.g. body length, hatching rate), the stimulatory response to MPs treatment was calculated using Formula (1). However, if a reduced response implied a positive effect (e.g. remaining diet, mortality rate), the stimulatory response was estimated by Formula (2). For the endpoint that was a biomarker of oxidative stress, the inhibitory response was computed via Formula (3).

$S R=R_{t} / R_{c} \times 100$

$S R=R_{c} / R_{t} \times 100$

$I R=R_{t} / R_{c} \times 100$

where $S R$ and $I R$ were the abbreviations for stimulatory response and inhibitory response, respectively, representing $\%$ of the control; $R_{t}$ and $R_{c}$ denoted the mean values of MPs-treated group and control group, respectively.

The combined response refers to combing all the same type responses (stimulatory or inhibitory) in individual studies into one response estimator. The combined response was calculated using meta-analysis that is a powerful statistical tool to increase the robustness of the pooled estimator across individual studies with the same topic by reducing or even eliminating (i.e. a given weight of 0 ) potential sampling error and extreme data (Gurevitch et al., 2018; Higgins et al., 2020). The Stata v.12.0 software (StataCorp, College Station, USA) was used to conduct this meta-analysis. The random-effects model based on the inverse-variance weighted method was used to synthesize the results of each study. This model could adjust the weight of each study by the between-study variance (Formulas (4)-(7)) (DerSimonian and Laird, 1986, 2015).

The between-study variance $\left(\tau^{2}\right)$ was computed using:

$$
\begin{aligned}
\tau^{2}= & {\left[\sum X_{i}\left(Y_{i}-\sum X_{i} Y_{i} / \sum X_{i}\right)^{2}-(k-1)\right] /\left(\sum X_{i}\right.} \\
& \left.-\sum X_{i}^{2} / \sum X_{i}\right)
\end{aligned}
$$

where $X_{i}, Y_{i}$ and $k$ were the inverse of variance of $i$ th study, the $i$ th effect estimate and the number of included studies, respectively.

The weight of $i$ th study $\left(W_{i}\right)$ was calculated by the random-effects model, as:

$W_{i}=1 /\left(V_{i}+\tau^{2}\right)$

where $V_{i}$ represented the variance of $i$ th study.

The combined response $\left(R_{o}\right)$ and its variance $\left(V_{R o}\right)$ were then calculated, as:

$R_{o}=\sum W_{i} Y_{i} / \sum W_{i}$

$V_{R o}=1 / \sum W_{i}$

The random-effects meta-regression techniques were used via the command metareg response variable, wsvar(variance) bsest(reml) randomsize in Stata software to examine whether the extents of the stimulatory/inhibitory responses vary between different response and exposure variables (Harbord and Higgins, 2008). The statistical uncertainty was quantified in $95 \%$ confidence intervals, and the significant level was set at $\alpha=0.05$.

\section{Results and discussion}

\subsection{Overview of included publications}

After final screening, a total of 43 papers, involving 270 endpoints of 3765 individuals, were included in this retrospective analysis (Table S1). Twenty-two studies were conducted on freshwater biota, and 21 studies on marine biota. Polystyrene (PS) was the most frequently selected polymer (28 studies), and sphere (including bead (de Ruijter et al., 2020)) was the most widely used shape (33 studies). The plastic size ranged from 0.05 to $2000 \mu \mathrm{m}$, with a median size of $2 \mu \mathrm{m}$. The mean and median values of the exposure duration were 13 and 9 days, respectively. The exposure concentrations varied between 0.008 and $1000 \mu \mathrm{g} / \mathrm{L}$, with a median concentration of $100 \mu \mathrm{g} / \mathrm{L}$.

\subsection{MPs-induced stimulatory/inhibitory responses at environmentally relevant concentrations}

The stimulatory responses of consumption, growth, reproduction and survival of aquatic biota exposed to MPs at environmentally relevant concentrations were significantly higher than the control levels $(p$ $<0.05$ ), which were $138 \%, 144 \%, 131 \%$ and $140 \%$ of the control, respectively, with a combined response of $136 \%$ (Fig. 2). The stimulation effect suggested that low concentration of MPs might be involved in the adaptive response of aquatic organisms, and act as a conditioning agent to strength biological performance and biological resistance (Guzzetti et al., 2018; Sun et al., 2018; Chen et al., 2020b). A previous meta-analysis of 43 publications conducted by Foley et al. (2018) showed that in many cases, MP administration to aquatic organisms had no significant influence on the biological performance indicators. It should be noted that the exposure concentration of MPs was not considered as a variable/restriction by Foley et al. (2018), meaning that environmentally unrealistic concentrations (e.g. $100 \mathrm{mg} / \mathrm{L}$ of MPs used in the included study (Jemec et al., 2016)) were also involved. However, when limited to environmentally relevant concentrations, some potentially positive effects might be observed due to the moderate inducer role of MPs. In addition, the random-effects meta-regression indicated that the extents of MPs-induced stimulatory responses did not differ significantly $(p>0.05)$ among measured endpoint (coefficient of

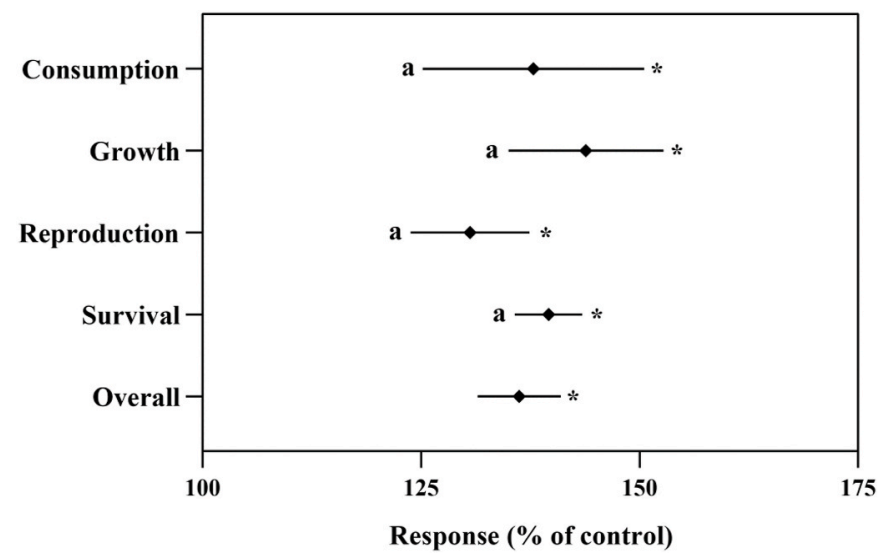

Fig. 2. The stimulatory response degrees of biological performance indicators. The same letters denoted that there was no statistical difference at $\alpha=0.05$ level among indicators. The asterisk $(*)$ indicated statistical difference $(p<$ 0.05 ) between control and MPs-treated groups. Data were represented by mean with $95 \%$ confidence intervals (CIs). 
variation $(\mathrm{CV})=4 \%$ ) (Fig. 2), habitat (Fig. 3a), MP composition (Fig. 3b), morphology (Fig. 3c), particle size (Fig. 3d), exposure duration (Fig. 3e) and exposure concentration (Fig. 3f), suggesting that aquatic organisms exposed to low concentrations of MPs exhibited generalized stimulation.

The inhibitory responses of oxidative stress biomarkers, including catalase (CAT), superoxide dismutase (SOD), glutathione peroxidase (GPx), glutathione-S-transferase (GST), glutathione (GSH), thiobarbituric acid reactive substances (TBARS), lipid peroxidation (LPO), maleic dialdehyde (MDA) and reactive oxygen species (ROS) were obviously lower than the control levels $(p<0.05)$, which were $69 \%$, $74 \%, 73 \%, 73 \%, 67 \%, 65 \%, 75 \%, 72 \%$ and $70 \%$ of the control, respectively, with a combined response of $71 \%$ (Fig. 4). The inhibition

\section{a}

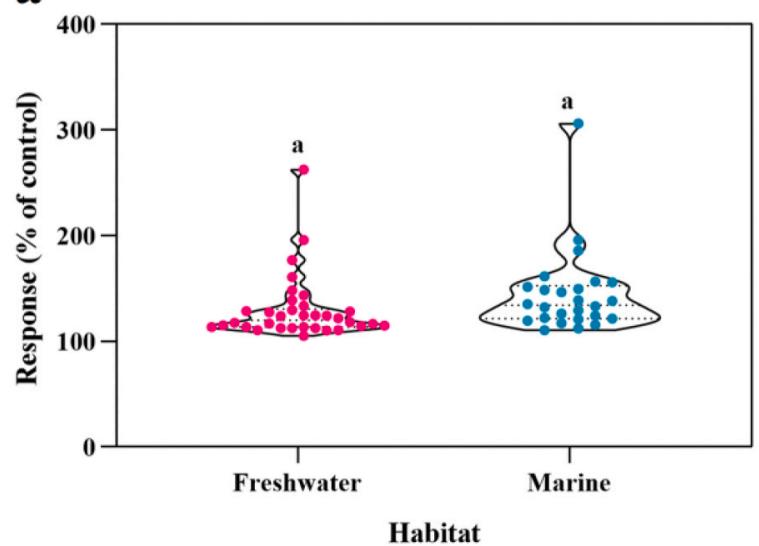

c

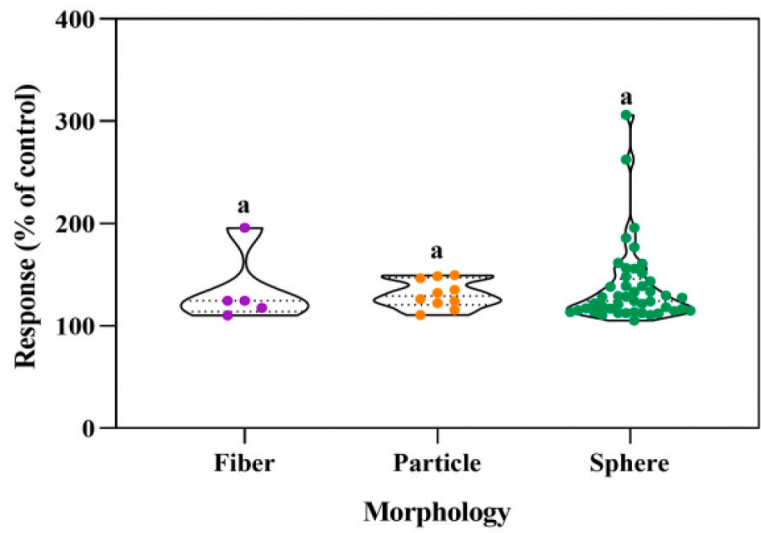

$\mathbf{e}$

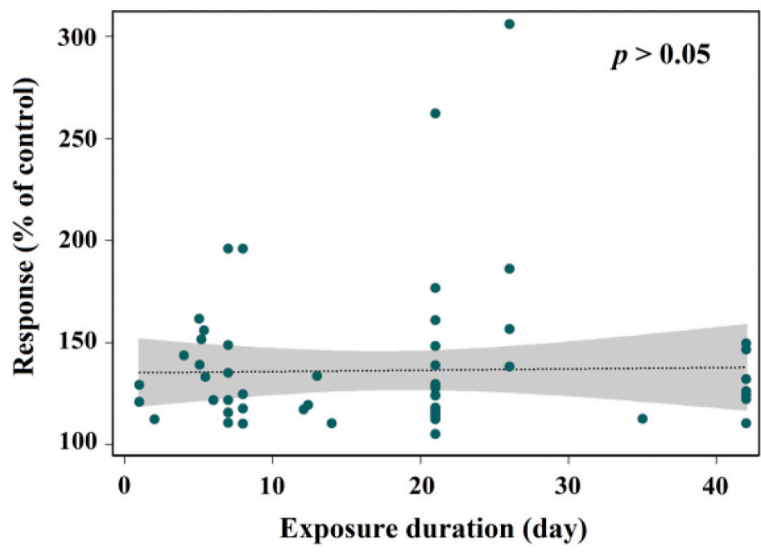

effect indicated that MP exposure influenced the functioning of the antioxidant system of aquatic organisms. The levels of MDA, TBARS, ROS and LPO were directly related to oxidative stress, among which MDA was the prototype of TBARS that stemmed from the ROS-mediated LPO (Cole et al., 2020; Kamal et al., 2020). Their reductions reflected the enhanced defense response and alleviated oxidative stress, suggesting that the antioxidant system might be dominated in these cases to maintain redox homeostasis (Jia et al., 2013). However, the decrease of other biomarkers did not necessarily mean that the redox maintained at a low steady-state level, but probably meant the imbalance of the antioxidant defense system (e.g. the decrease of GSH might negatively affect the antioxidant capacity), which need to be further explored and clarified (Trestrail et al., 2020; Kim et al., 2021). Additionally, the

b

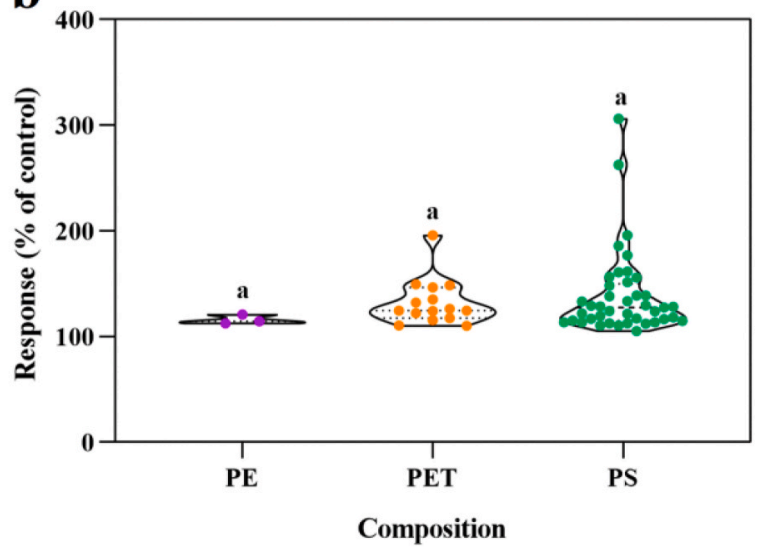

d

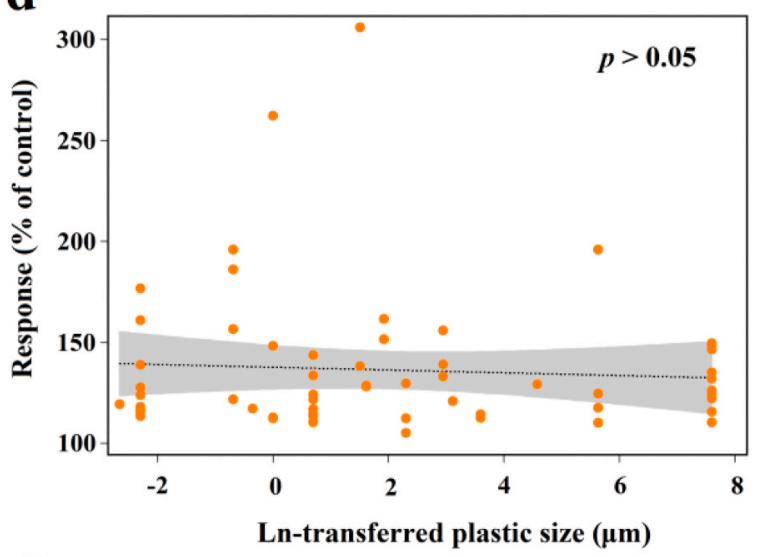

f

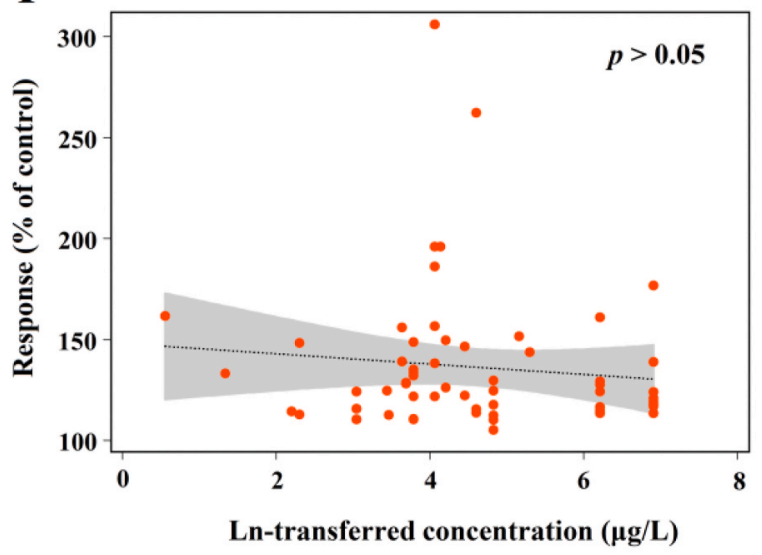

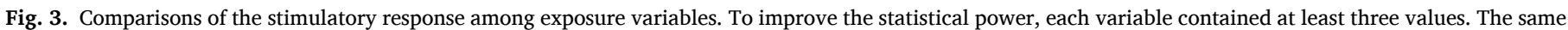
letter meant no significant difference $(p>0.05)$. Abbreviations: PE, polyethylene; PET, polyethylene terephthalate; PS, polystyrene. 


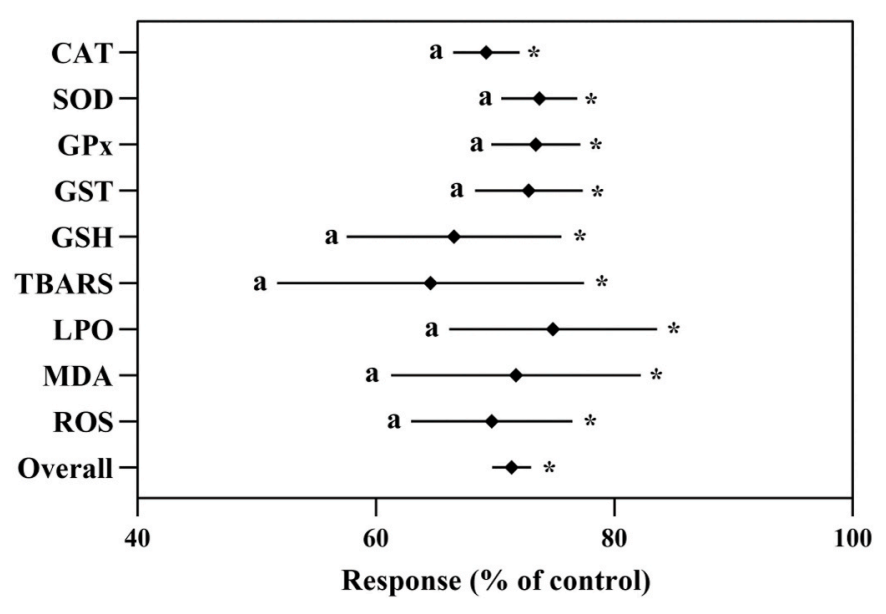

Fig. 4. The inhibitory response extents of oxidative stress biomarkers. The same letters indicated no significant difference among biomarkers $(p>0.05)$. Data were represented by mean with $95 \%$ CIs. The asterisk $(*)$ indicated statistical difference $(p<0.05)$ between control and MPs-treated groups. Abbreviations: CAT, catalase; SOD, superoxide dismutase; GPx, glutathione peroxidase; GST, glutathione-S-transferase; GSH, glutathione; TBARS, thiobarbituric acid reactive substances; LPO, lipid peroxidation; MDA, maleic dialdehyde; ROS, reactive oxygen species.

random-effects meta-regression showed that the extents of the inhibitory responses were also independent of measured endpoint $(\mathrm{CV}=5 \%)$ (Fig. 4), habitat (Fig. 5a), MP composition (Fig. 5b), morphology (Fig. 5c), particle size (Fig. 5d) and exposure duration (Fig. 5e). Intriguingly, at the cellular/molecular level where responses tended to be more sensitive than the individual level (Zhang et al., 2009), a significant concentration-dependent inhibitory response was observed ( $p$ $<0.01$ ) (Fig. 5f). The concentration-dependent inhibition might be explained by (i) the concentration of MPs did not exceed the threshold of disrupting redox homeostasis; (ii) the increased MP stress could activate the antioxidant system more effectively; (iii) this activation would enhance the defense response and trigger a powerful compensatory reaction to protect against more severe stress (Calabrese, 2001; Jia et al., 2013; Prokić et al., 2019).

In addition, it should be noted that the tested animals at different life stages might have dissimilar accumulation abilities of MPs (Woods et al., 2020), and the enrichment of MPs from the supplement food/prey during the exposure period might occur (Carbery et al., 2018; Hasegawa and Nakaoka, 2021). However, these factors that potentially influence the effect of MPs are easily ignored. Therefore, it is highly recommended that the detailed life stages of the tested animals and the concentration of MPs in food/prey should be measured and reported in future studies to increase the comparability between studies and avoid speculation.

\subsection{Evidence of MPs-induced hormetic dose response relationships}

The observed effects of MPs on enhancing biological performance and reducing oxidative stress biomarkers challenged our previous understanding of the toxicity of MPs, suggesting that the effects of MPs could not be roughly considered as adverse events, especially at environmentally relevant concentrations. These observations also presented a very interesting hypothesis, that was, with the increase of exposure concentrations, the effects of MPs on aquatic biota might be opposite/ non-monotonic. Correspondingly, the hormetic dose response relationships were identified with various endpoints tested (Fig. 6a-i), which provided a novel insight for understanding the complex effects of MPs.

To evaluate the influence of MPs on the biological performance of aquatic biota, Ziajahromi et al. (2017) investigated the effect of an 8-day exposure to polyethylene terephthalate (PET) microfibers $(280 \mu \mathrm{m})$ on the reproduction of Ceriodaphnia dubia. It was shown that the number of neonates in the second brood of $C$. dubia was significantly stimulated at $62.5 \mu \mathrm{g} / \mathrm{L}$ (196\% of the control), but inhibited continuously with the increase of exposure concentrations, presenting an inverted U-shaped hormetic dose response relationship (Fig. 6a).

In terms of oxidative stress biomarkers, after exposure to PS MPs (5 $\mu \mathrm{m})$ for 21 days, the MDA contents of Eriocheir sinensis in MPs-treated groups decreased by $25 \%$ and $31 \%$ at concentrations of 40 and 400 $\mu \mathrm{g} / \mathrm{L}$, respectively, but obviously increased by $80 \%$ at $40000 \mu \mathrm{g} / \mathrm{L}$, presenting a J-shaped hormetic relationship (Fig. 6b) (Yu et al., 2018). Moreover, in the study of Yu et al. (2018), an inverted U-shaped hormetic curve of SOD activity was also observed (Fig. 6c). It could be explained that moderate oxidative stress induced by low concentration of MPs could stimulate the activity of SOD, while severe oxidative stress caused by the increased MP concentration exceeded the limit of antioxidative capacity, thereby resulting in the disruption/collapse of antioxidant system and the inhibition of SOD activity (Trestrail et al., 2020).

To evaluate the potential genotoxicity of MPs, Yu and Chan (2020) investigated the transgenerational effect of PS MPs on Amphibalanus Amphitrite. It was shown that parental $\left(\mathrm{F}_{0}\right)$ exposure to $19 \mu \mathrm{m} \mathrm{MP}$ at 380 $\mu \mathrm{g} / \mathrm{L}$ could decrease the development time of offspring larval $\left(\mathrm{F}_{1}\right)$ by $15 \%$. However, when the exposure concentration of $F_{0}$ reached 3800 $\mu \mathrm{g} / \mathrm{L}$, the development time of $\mathrm{F}_{1}$ increased to $107 \%$ of the control. The transgenerational effect of MPs presented a J-shaped hormetic relationship (Fig. 6d). At molecular level, Revel et al. (2020) showed that the percentages of tailed DNA in Crassostrea gigas after exposure to $0.008-100 \mu \mathrm{g} / \mathrm{L}$ polyethylene-polypropylene MPs $(<400 \mu \mathrm{m})$ were lower than those in the control group, suggesting that environmentally realistic exposure to MPs did not cause DNA damage. However, when exposure to unrealistic concentrations $(56,100,180 \mathrm{mg} / \mathrm{L})$, significant increases in DNA damage were exhibited, reflected by the number of DNA strand breaks increased up to 2-fold, 11-fold and 15-fold, respectively, compared to the control (Alnajar et al., 2021).

For the immunotoxicity of MPs, juveniles of $E$. sinensis were exposed to different concentrations of $5 \mu \mathrm{m}$ MP for 14 days, showing that the activity of lysozyme (LSZ) in hepatopancreas increased significantly at $400 \mu \mathrm{g} / \mathrm{L}$ (138\% of the control) and then decreased continuously with the increase of MPs ( $96 \%$ and $90 \%$ of the control at 4000 and $40000 \mu \mathrm{g} /$ $\mathrm{L}$, respectively), presenting an inverted U-shaped hormetic curve (Fig. 6e) (Liu et al., 2019). Consistently, other immune parameters in haemolymph of $E$. sinensis were also displayed inverted U-shaped hormetic curves, such as phenoloxidase activity (PO) (Fig. 6f) and acid phosphatase activity (Fig. 6g). Intriguingly, the disappearance of hormesis of PO after 21 days of exposure indicated that the hormetic effect might be temporary at some endpoints (Oberbaum et al., 2010).

To determine the neurotoxicity of MPs, Li et al. (2020) explored whether PS MPs $(0.08 \mu \mathrm{m})$ could trigger nervous system response of Corbicula fluminea. It was shown that after exposure to different concentrations of MPs for $96 \mathrm{~h}$, the activity of acetylcholinesterase (AChE) in gill increased by $17 \%$ and decreased by $3 \%$ at $100 \mu \mathrm{g} / \mathrm{L}$ and 5000 $\mu \mathrm{g} / \mathrm{L}$, respectively, exhibiting an inverted U-shaped hormetic curve (Fig. 6h). At environmentally relevant concentrations (1, 10, 100, 1000 $\mu \mathrm{g} / \mathrm{L}$ ), Gambardella et al. (2017) reported that the activities of AChE in A. amphitrite significantly increased at all tested concentrations. However, the neurotoxicity of MPs at high concentrations has also been widely documented (Prokić et al., 2019; Bhagat et al., 2020; Eom et al., 2020).

In terms of behavioral alteration, Gambardella et al. (2018) showed that the swimming speed of Brachionus plicatilis changed after exposure to environmentally relevant $(1 \mu \mathrm{g} / \mathrm{L})$ and unrealistic $(10000 \mu \mathrm{g} / \mathrm{L})$ concentrations of MPs, which were $137 \%$ and $68 \%$ of the control, respectively, displaying an inverted U-shaped hormetic relationship (Fig. 6i). Moreover, Chen et al. (2020a) reported that zebrafish became hyperactive after exposure to $5 \mu \mathrm{m} \mathrm{MP}$ at $1000 \mu \mathrm{g} / \mathrm{L}$, reflected by the significantly increased moved distance (averaged 163\% of the control). However, when exposed to environmentally unrealistic concentrations, the hyperactive behavior of zebrafish did not appear, and was replaced 
$\mathbf{a}$

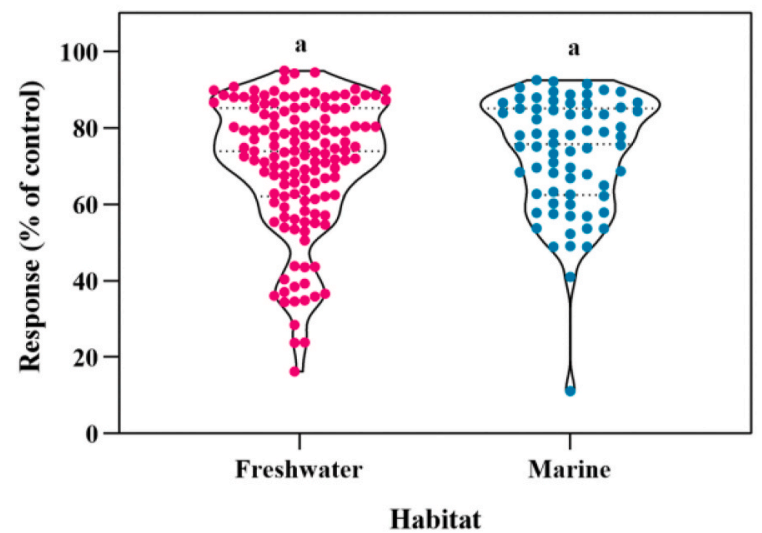

c

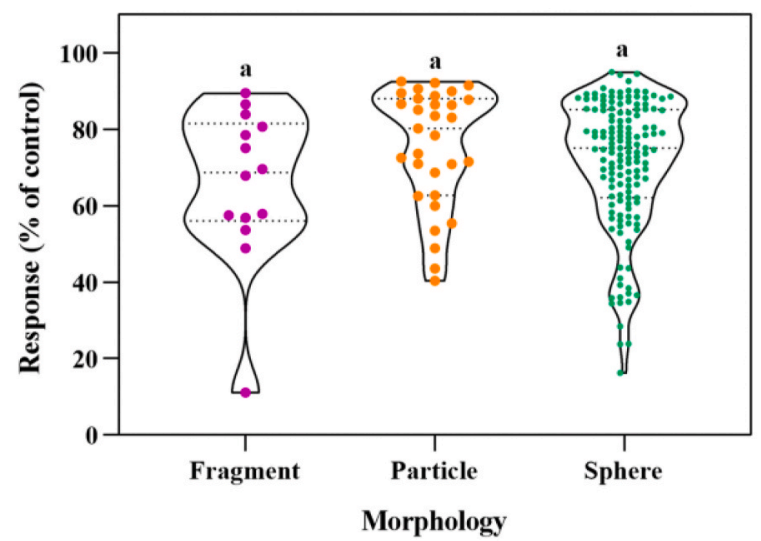

$\mathbf{e}$

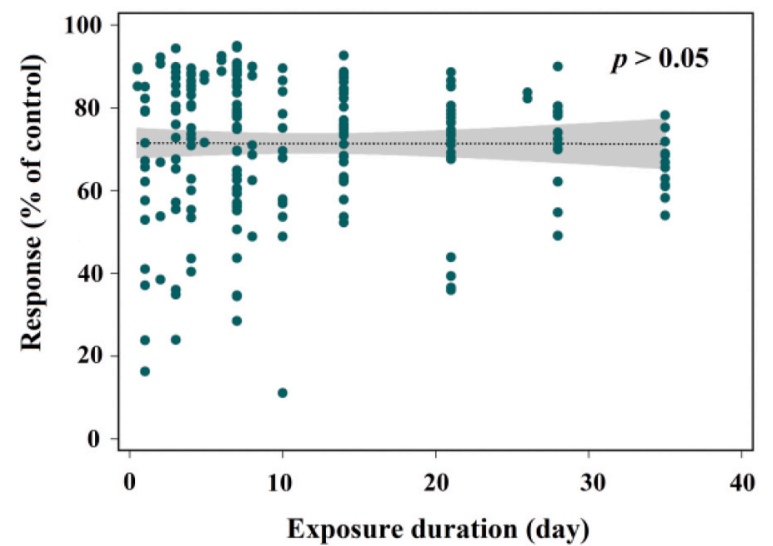

b

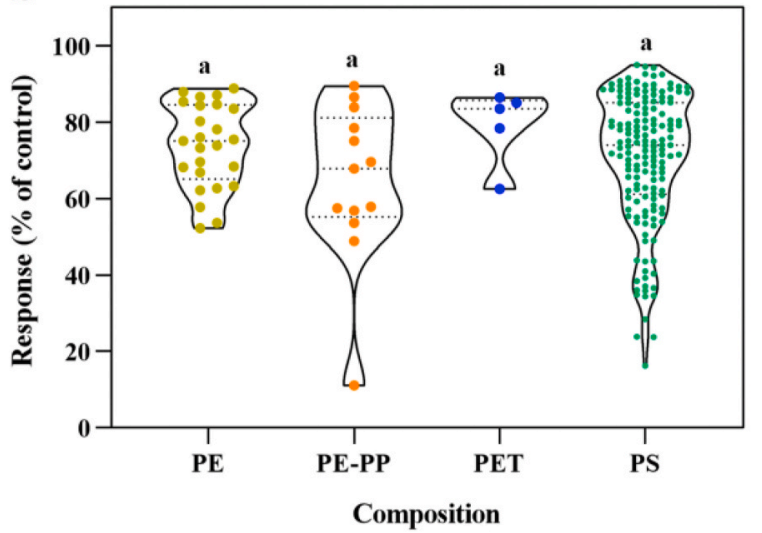

d

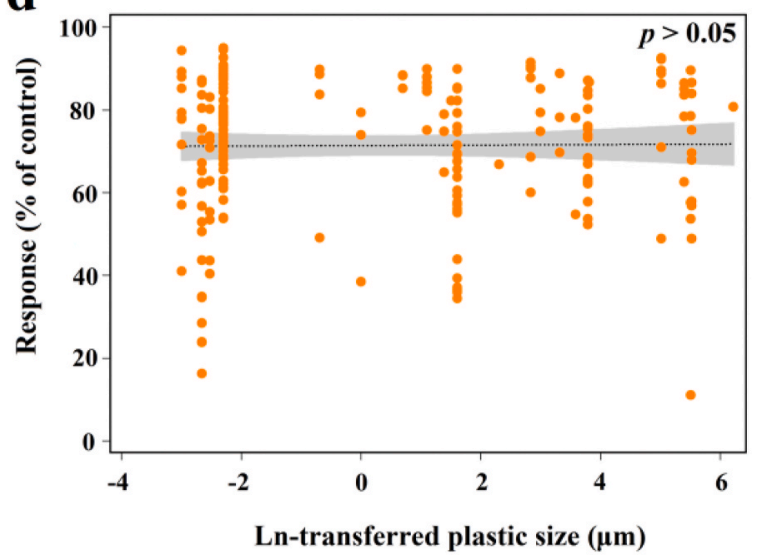

f

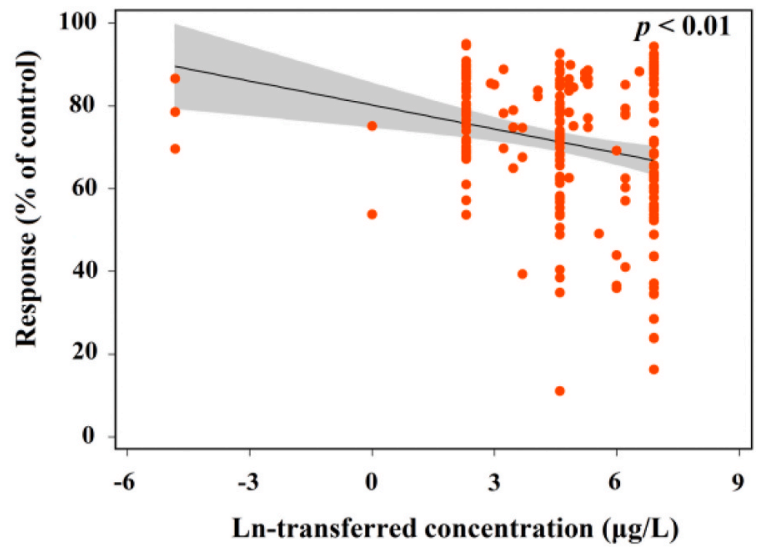

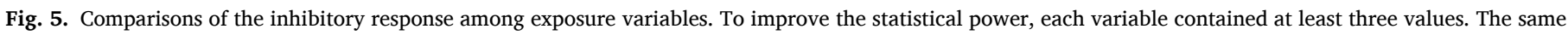

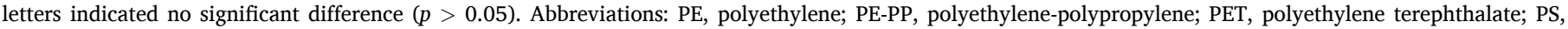
polystyrene.

by reduced activity or even inactivity. For example, Santos et al. (2021) showed that after exposure to $2000 \mu \mathrm{g} / \mathrm{L} 1-5 \mu \mathrm{m} \mathrm{MP}$, the moved distance of zebrafish in MPs-treated group was only $81 \%$ of the control.

Taken together, this section provided evidence/examples to indicate that MPs, as a stressor agent, could induce hormetic dose response relationship in aquatic biota, and the shape of the hormetic curve depended on that endpoint.

\subsection{Application of hormetic model in risk assessment of MPs}

The linear no-threshold (LNT) model, threshold model and hormetic model are the main dose response models used in toxicology and risk assessment (Agathokleous et al., 2019a). Among them, the LNT model assumes that the response starts linearly from zero dose (Fig. 7a), while the threshold model supposes that the response only appears above a threshold dose (Fig. 7b). However, the hormetic model presumes the occurrence of modest response at low dose and the opposite response at high dose (Fig. 7c) (Hashmi et al., 2014; Agathokleous et al., 2019b).

At present, the hormetic model has attracted considerable interest and has been recommended as a default toxicological model (Sun et al., 2020). The hormetic dose response model appears to be more common than the LNT and threshold models (Calabrese and Baldwin, 2003; Doss, 2013; Cardarelli II and Ulsh, 2018; Costantini and Borremans, 2019), which has been documented in diverse biological models, various agents 

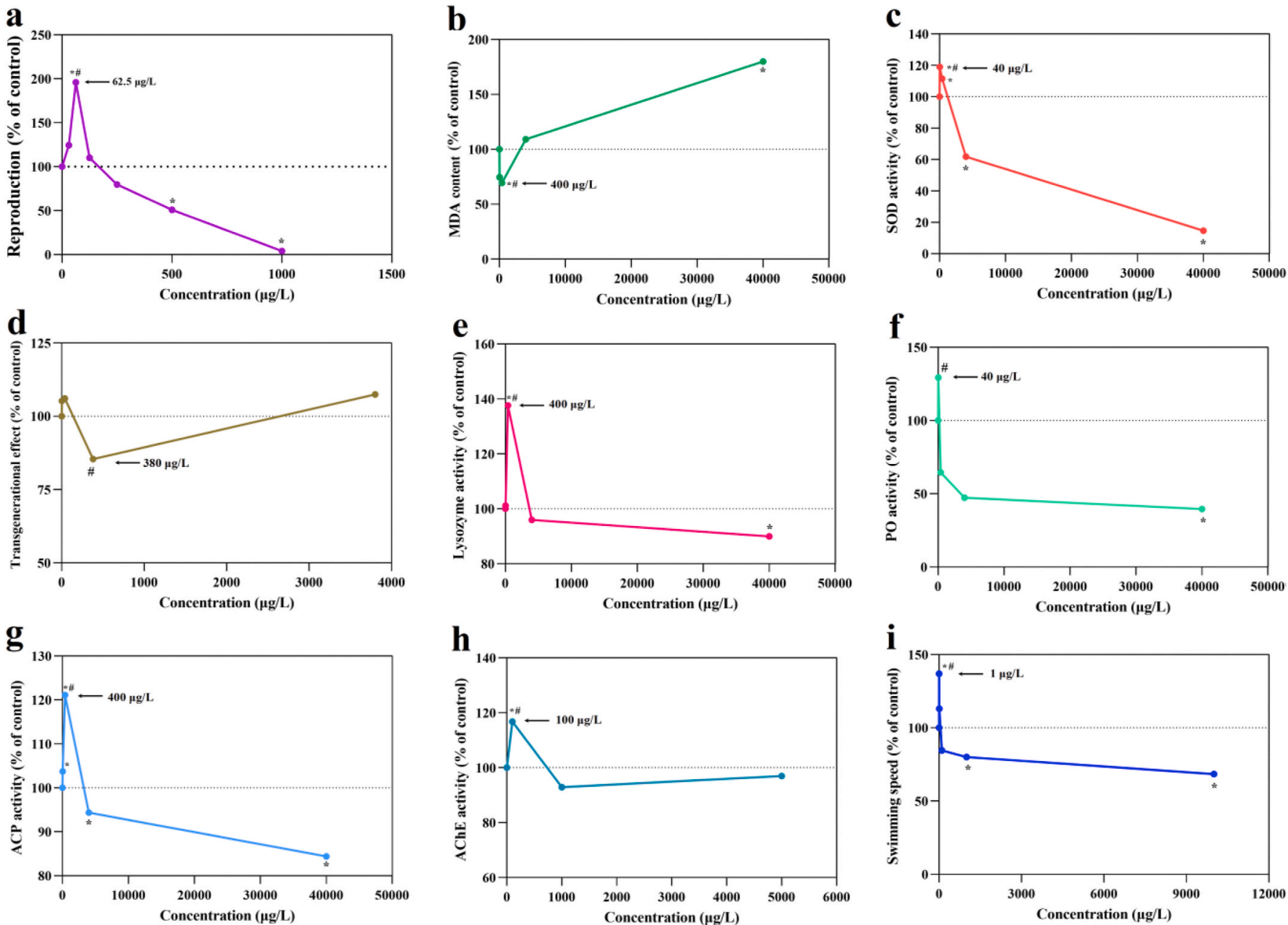

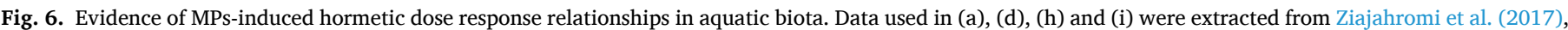

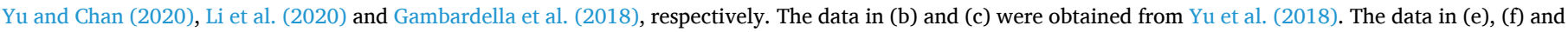

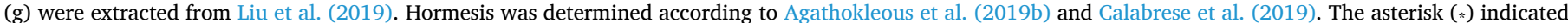

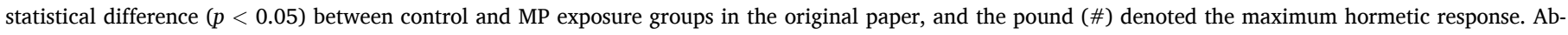
breviations: AChE, acetylcholinesterase; ACP, acid phosphatase; MDA, maleic dialdehyde; PO, phenoloxidase, SOD, superoxide dismutase.

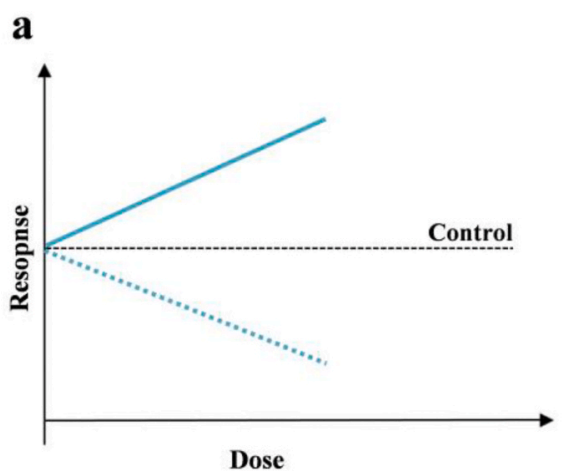

Linear no-threshold model

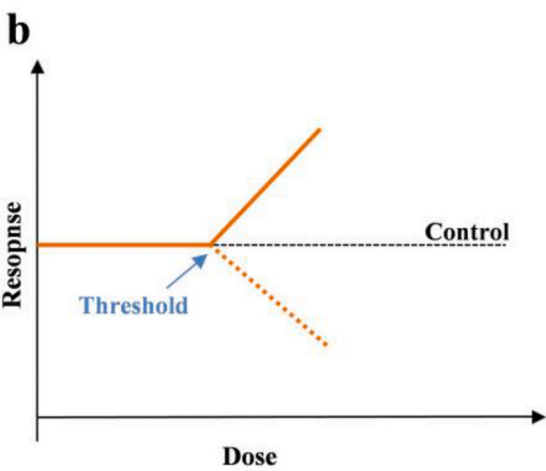

Threshold model

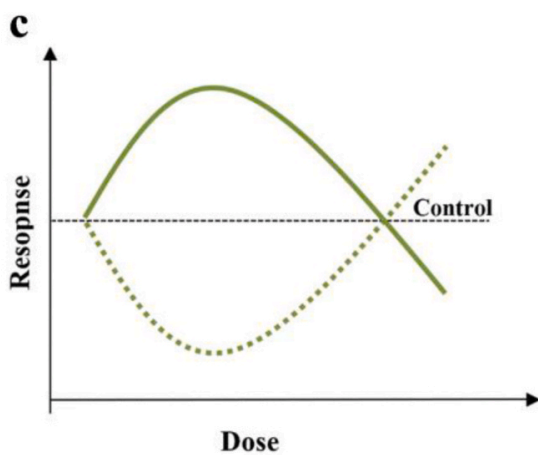

Hormetic model

Fig. 7. The dose response models of linear no-threshold model (a), threshold model (b) and hormetic model (c).

and numerous endpoints (Calabrese and Blain, 2011; Viebahn-Hänsler et al., 2012; Rattan et al., 2013; Vandenberg, 2014; Le Bourg, 2015; Mytych et al., 2016; Pennisi et al., 2017; Shibamoto and Nakamura, 2018; Calabrese et al., 2019; Campos et al., 2019; Santoro et al., 2020). The current study provided various evidence for the occurrence of hormetic dose response relationships in aquatic organisms exposed to
MPs (see Fig. 6 for examples). These dose response relationships (i.e. $\mathrm{J}$-shaped or inverted U-shaped) highlighted the insufficiency of applying LNT/threshold model to predict the toxicity of MPs at low concentrations, while the hormetic model could provide more accurate prediction in the zone below the threshold (Calabrese, 2012). Therefore, MPs-induced hormesis needs to be considered in future MP toxicity 
studies, and the hormetic model should be applied to the ecologica1/environmental risk assessment of MPs.

\section{Conclusions}

The present study provided substantial evidence for the onset of enhanced biological performance and reduced oxidative stress biomarkers in aquatic biota induced by MPs at environmentally relevant concentrations $(\leq 1 \mathrm{mg} / \mathrm{L}$, median $=0.1 \mathrm{mg} / \mathrm{L})$. The extents of the stimulatory responses (131\%-144\% of the control) and inhibitory responses $(65 \%-75 \%$ of the control) were typically generalizable, independent of measured endpoint, habitat, MP composition, morphology, particle size and exposure duration. However, the inhibitory response of oxidative stress biomarkers exhibited a significant concentrationdependent manner. In addition, various endpoints presented J-shaped or inverted U-shaped hormetic dose response relationships, highlighting that the hormetic model should be considered in the risk assessment of MPs.

\section{Declaration of competing interest}

The authors declare that they have no known competing financial interests or personal relationships that could have appeared to influence the work reported in this paper.

\section{Acknowledgments}

We thank three anonymous reviewers for their constructive comments and helpful suggestions. We also thank the authors of the included papers for their excellent work and kind help. This research was supported by the grants from National Natural Science Foundation of China (42076164) and the Young Taishan Scholars Program of Shandong Province for Prof. Huifeng Wu (tsqn201812115).

\section{Appendix A. Supplementary data}

Supplementary data to this article can be found online at https://doi. org/10.1016/j.envpol.2021.117206.

\section{Credit author contribution statement}

Tao Sun: Methodology, Formal analysis, Writing - original draft. Junfei Zhan: Formal analysis., Fei Li: Writing - review \& editing. Chenglong Ji: Writing - review \& editing. Huifeng Wu: Supervision, Writing - review \& editing, Project administration.

\section{References}

Agathokleous, E., Belz, R.G., Calatayud, V., De Marco, A., Hoshika, Y., Kitao, M. Saitanis, C.J., Sicard, P., Paoletti, E., Calabrese, E.J., 2019a. Predicting the effect of ozone on vegetation via linear non-threshold (LNT), threshold and hormetic doseresponse models. Sci. Total Environ. 649, 61-74.

Agathokleous, E., Araminiene, V., Belz, R.G., Calatayud, V., De Marco, A., Domingos, M., Feng, Z., Hoshika, Y., Kitao, M., Koike, T., Paoletti, E., Saitanis, C.J., Sicard, P., Calabrese, E.J., 2019b. A quantitative assessment of hormetic responses of plants to ozone. Environ. Res. 176, 108527.

Alnajar, N., Jha, A.N., Turner, A., 2021. Impacts of microplastic fibres on the marine mussel, Mytilus galloprovinciallis. Chemosphere 262, 128290.

Anderson, J.C., Park, B.J., Palace, V.P., 2016. Microplastics in aquatic environments: implications for Canadian ecosystems. Environ. Pollut. 218, 269-280.

Biais, M., de Courson, H., Lanchon, R., Pereira, B., Bardonneau, G., Griton, M., Sesay, M., Nouette-Gaulain, K., 2017. Mini-fluid challenge of $100 \mathrm{ml}$ of crystalloid predicts fluid responsiveness in the operating room. Anesthesiology 127, 450-456.

Besseling, E., Redondo-Hasselerharm, P., Foekema, E.M., Koelmans, A.A., 2019. Quantifying ecological risks of aquatic micro- and nanoplastic. Crit. Rev. Environ. Sci. Technol. 49, 32-80.

Bhagat, J., Nishimura, N., Shimada, Y., 2020. Toxicological interactions of microplastics/ nanoplastics and environmental contaminants: current knowledge and future perspectives. J. Hazard Mater. 123913.
Bouwmeester, H., Peter, C.H.H., Ruud, J.B.P., 2015. Potential health impact of environmentally released micro- and nanoplastics in the human food production chain: experiences from nanotoxicology. Environ. Sci. Technol. 49, 8932-8947.

Brennecke, D., Duarte, B., Paiva, F., Caçador, I., Canning-Clode, J., 2016. Microplastics as vector for heavy metal contamination from the marine environment. Estuar. Coast Shelf Sci. 178, 189-195.

Burns, E.E., Boxall, A.B.A., 2018. Microplastics in the aquatic environment: evidence for or against adverse impacts and major knowledge gaps. Environ. Toxicol. Chem. 37, 2776-2796.

Calabrese, E.J., 2001. Overcompensation stimulation: a mechanism for hormetic effects. Crit. Rev. Toxicol. 31, 425-470.

Calabrese, E.J., 2012. Hormesis: improving predictions in the low-dose zone. In: Luch, A. (Ed.), Molecular, Clinical and Environmental Toxicology. Springer, Berlin, pp. 551-564.

Calabrese, E.J., 2013. Biphasic dose responses in biology, toxicology and medicine: accounting for their generalizability and quantitative features. Environ. Pollut. 182, $452-460$.

Calabrese, E.J., Agathokleous, E., Kapoor, R., Kozumbo, W.J., Rattan, S.I.S., 2019. Reanalysis of herbal extracts data reveals that inflammatory processes are mediated by hormetic mechanisms. Chem. Biol. Interact. 314, 108844.

Calabrese, E.J., Baldwin, L.A., 2003. The hormetic dose response model is more common than the threshold model in toxicology. Toxicol. Sci. 71, 246-250.

Calabrese, E.J., Blain, R.B., 2011. The hormesis database: the occurrence of hormetic dose responses in the toxicological literature. Regul. Toxicol. Pharmacol. 61, 73-81.

Calabrese, E.J., Dhawan, G., Kapoor, R., Iavicoli, I., Calabrese, V., 2016. Hormesis: a fundamental concept with widespread biological and biomedical applications. Gerontology 62, 530-535.

Campos, S.O., Santana, I.V., Silva, C., Santos-Amaya, O.F., Guedes, R.N.C., Pereira, E.J. G., 2019. Bt-induced hormesis in Bt-resistant insects: theoretical possibility or factual concern? Ecotox. Environ. Saf. 183, 109577.

Carbery, M., O'Connor, W., Palanisami, T., 2018. Trophic transfer of microplastics and mixed contaminants in the marine food web and implications for human health. Environ. Int. 115, 400-409.

Cardarelli II, J.J., Ulsh, B.A., 2018. It is time to move beyond the linear no-threshold theory for low-dose radiation protection. Dose-Response 16, 1-24.

Chen, Q., Lackmann, C., Wang, W., Seiler, T.B., Hollert, H., Shi, H., 2020a. Microplastics lead to hyperactive swimming behaviour in adult zebrafish. Aquat. Toxicol. 224, 105521.

Chen, Q., Li, Y., Li, B., 2020b. Is color a matter of concern during microplastic exposure to Scenedesmus obliquus and Daphnia magna? J. Hazard Mater. 383, 121224.

Cole, M., Lindeque, P., Halsband, C., Galloway, T.S., 2011. Microplastics as contaminants in the marine environment: a review. Mar. Pollut. Bull. 62, 2588-2597.

Cole, M., Liddle, C., Consolandi, G., Drago, C., Hird, C., Lindeque, P.K., Galloway, T.S., 2020. Microplastics, microfibres and nanoplastics cause variable sub-lethal responses in mussels (Mytilus spp.). Mar. Pollut. Bull. 160, 111552.

Costantini, D., Borremans, B., 2019. The linear no-threshold model is less realistic than threshold or hormesis-based models: an evolutionary perspective. Chem. Biol. Interact. 301, 26-33.

de Ruijter, V.N., Redondo-Hasselerharm, P.E., Gouin, T., Koelmans, A.A., 2020. Quality criteria for microplastic effect studies in the context of risk assessment: a critical review. Environ. Sci. Technol. 54, 11692-11705.

de Sá, L.C., Oliveira, M., Ribeiro, F., Rocha, T.L., Futter, M.N., 2018. Studies of the effects of microplastics on aquatic organisms: what do we know and where should we focus our efforts in the future? Sci. Total Environ. 645, 1029-1039.

de Souza Machado, A.A., Kloas, W., Zarfl, C., Hempel, S., Rillig, M.C., 2018. Microplastics as an emerging threat to terrestrial ecosystems. Global Change Biol. 24, 1405-1416.

DerSimonian, R., Laird, N., 1986. Meta-analysis in clinical trials. Contr. Clin. Trials 7 , $177-188$.

DerSimonian, R., Laird, N., 2015. Meta-analysis in clinical trials revisited. Contemp. Clin. Trials 45, 139-145.

Doss, M., 2013. Linear no-threshold model vs. radiation hormesis. Dose-Response 11, 480-497.

Eom, H.J., Nam, S.E., Rhee, J.S., 2020. Polystyrene microplastics induce mortality through acute cell stress and inhibition of cholinergic activity in a brine shrimp. Mol. Cell. Toxicol. 16, 233-243.

Foley, C.J., Feiner, Z.S., Malinich, T.D., Höok, T.O., 2018. A meta-analysis of the effects of exposure to microplastics on fish and aquatic invertebrates. Sci. Total Environ. 631-632, 550-559.

Franzellitti, S., Canesi, L., Auguste, M., Wathsala, R.H.G.R., Fabbri, E., 2019. Microplastic exposure and effects in aquatic organisms: a physiological perspective. Environ. Toxicol. Pharmacol. 68, 37-51.

Galloway, T.S., Cole, M., Lewis, C., 2017. Interactions of microplastic debris throughout the marine ecosystem. Nat. Ecol. Evol. 1, 116.

Gambardella, C., Morgana, S., Ferrando, S., Bramini, M., Piazza, V., Costa, E., Garaventa, F., Faimali, M., 2017. Effects of polystyrene microbeads in marine planktonic crustaceans. Ecotoxicol. Environ. Saf. 145, 250-257.

Gambardella, C., Morgana, S., Bramini, M., Rotini, A., Manfra, L., Migliore, L., Piazza, V., Garaventa, F., Faimali, M., 2018. Ecotoxicological effects of polystyrene microbeads in a battery of marine organisms belonging to different trophic levels. Mar. Environ. Res. 141, 313-321.

Garcés-Ordóñez, O., Mejía-Esquivia, K.A., Sierra-Labastidas, T., Patiño, A., Blandón, L. M., Díaz, L.F.E., 2020. Prevalence of microplastic contamination in the digestive tract of fishes from mangrove ecosystem in Cispata, Colombian Caribbean. Mar. Pollut. Bull. 154, 111085. 
Geyer, R., 2020. Production, use, and fate of synthetic polymers. In: Letcher, T.M. (Ed.), Plastic Waste and Recycling: Environmental Impact, Societal Issues, Prevention, and Solutions. Academic Press, pp. 13-32. https://doi.org/10.1016/B978-0-12-8178805.00002-5.

Gurevitch, J., Koricheva, J., Nakagawa, S., Stewart, G., 2018. Meta-analysis and the science of research synthesis. Nature 555, 175-182.

Guzzetti, E., Sureda, A., Tejada, S., Faggio, C., 2018. Microplastic in marine organism: environmental and toxicological effects. Environ. Toxicol. Pharmacol. 64, 164-171.

Harbord, R.M., Higgins, J.P.T., 2008. Meta-regression in Stata. STATA J. 8, 493-519.

Hasegawa, T., Nakaoka, M., 2021. Trophic transfer of microplastics from mysids to fish greatly exceeds direct ingestion from the water column. Environ. Pollut. 273, 116468.

Hashmi, M.Z., Naveedullah Shen, H., Zhu, S., Yu, C., Shen, C., 2014. Growth, bioluminescence and shoal behavior hormetic responses to inorganic and/or organic chemicals: a review. Environ. Int. 64, 28-39.

Higgins, J.P.T., Thomas, J., Chandler, J., Cumpston, M., Li, T., Page, M.J., Welch, V.A. 2020. Cochrane Handbook for Systematic Reviews of Interventions. https://training. cochrane.org/handbook.

Jambeck, J.R., Geyer, R., Wilcox, C., Siegler, T.R., Perryman, M., Andrady, A., Narayan, R., Law, K.L., 2015. Plastic waste inputs from land into the ocean. Science 347, 768-771.

Jemec, A., Horvat, P., Kunej, U., Bele, M., Krzan, A., 2016. Uptake and effects of microplastic textile fibers on freshwater crustacean Daphnia magna. Environ. Pollut. 219, 201-209.

Jia, L., He, X., Chen, W., Liu, Z., Huang, Y., Yu, S., 2013. Hormesis phenomena under Cd stress in a hyperaccumulator-Lonicera japonica Thunb. Ecotoxicology 22, 476-485.

Kamal, H.M., El Fallah, A.A., Abdelbaki, S.A., Khalil, M.M., Kamal, M.M., Behiry, E.G., 2020. Association between seminal granulysin and malondialdehyde in infertile men with varicocele and the potential effect of varicocelectomy. Andrologia 52, e13579.

Kane, I.A., Clare, M.A., Miramontes, E., Wogelius, R., Rothwell, J.J., Garreau, P., Pohl, F., 2020. Seafloor microplastic hotspots controlled by deep-sea circulation. Science 368, 1140-1145.

Kim, J.H., Yu, Y.B., Choi, J.H., 2021. Toxic effects on bioaccumulation, hematological parameters, oxidative stress, immune responses and neurotoxicity in fish exposed to microplastics: a review. J. Hazard Mater. 413, 125423.

Klingelhöfer, D., Braun, M., Quarcoo, D., Brüggmann, D., Groneberg, D.A., 2020. Research landscape of a global environmental challenge: Microplastics. Water Res. $170,115358$.

Laffosse, J.M., Aubin, K., Lavigne, M., Roy, A., Vendittoli, P.A., 2011. Radiographic changes of the femoral neck after total hip resurfacing. Orthop. Traumatol. Surg. Res. 97, 229-240.

Le Bourg, É., 2015. Fasting and other mild stresses with hormetic effects in Drosophila melanogaster can additively increase resistance to cold. Biogerontology 16, 517-527.

Le Bourg, É., 2019. Mild stress-induced hormesis: hopes and challenges. In: Rattan, S.I.S., Kyriazis, M. (Eds.), The Science of Hormesis in Health and Longevity. Academic Press, London, pp. 25-33.

Lenz, R., Enders, K., Nielsen, T.G., 2016. Microplastic exposure studies should be environmentally realistic. Proc. Natl. Acad. Sci. Unit. States Am. 113, E4121-E4122.

Leslie, H.A., Brandsma, S.H., van Velzen, M.J.M., Vethaak, A.D., 2017. Microplastics en route: field measurements in the Dutch river delta and Amsterdam canals, wastewater treatment plants, North Sea sediments and biota. Environ. Int. 101, 133-142.

Li, Z., Feng, C., Wu, Y., Guo, X., 2020. Impacts of nanoplastics on bivalve: fluorescence tracing of organ accumulation, oxidative stress and damage. J. Hazard Mater. 392, 122418.

Liu, Z., Yu, P., Cai, M., Wu, D., Zhang, M., Chen, M., Zhao, Y., 2019. Effects of microplastics on the innate immunity and intestinal microflora of juvenile Eriocheir sinensis. Sci. Total Environ. 685, 836-846.

Ma, H., Pu, S., Liu, S., Bai, Y., Mandal, S., Xing, B., 2020. Microplastics in aquatic environments: toxicity to trigger ecological consequences. Environ. Pollut. 261, 114089.

MacArthur, D.E., 2017. Beyond plastic waste. Science 358, 843.

Mattson, M.P., 2008. Hormesis defined. Ageing Res. Rev. 7, 1-7.

Mazidi, M., Rezaie, P., Karimi, E., Kengne, A.P., 2017. The effects of bile acid sequestrants on lipid profile and blood glucose concentrations: a systematic review and meta-analysis of randomized controlled trials. Int. J. Cardiol. 227, 850-857.

Mytych, J., Wnuk, M., Rattan, S.I.S., 2016. Low doses of nanodiamonds and silica nanoparticles have beneficial hormetic effects in normal human skin fibroblasts in culture. Chemosphere 148, 307-315.

Oberbaum, M., Singer, S.R., Samuels, N., 2010. Hormesis and homeopathy: bridge over troubled waters. Hum. Exp. Toxicol. 29, 567-571.

O’Donovan, S., Mestre, N.C., Abel, S., Fonseca, T.G., Carteny, C.C., Cormier, B., Keiter, S. H., Bebianno, M.J., 2018. Ecotoxicological effects of chemical contaminants adsorbed to microplastics in the clam Scrobicularia plana. Front. Mar. Sci. 5, 143.

Ostle, C., Thompson, R.C., Broughton, D., Gregory, L., Wootton, M., Johns, D.G., 2019 The rise in ocean plastics evidenced from a 60-year time series. Nat. Commun. 10, 1622.

Pahl, S., Wyles, K.J., Thompson, R.C., 2017. Channelling passion for the ocean towards plastic pollution. Nat. Hum. Behav, 1, 697-699.

Pennisi, M., Crupi, R., Di Paola, R., Ontario, M.L., Bella, R., Calabrese, E.J., Crea, R., Cuzzocrea, S., Calabrese, V., 2017. Inflammasomes, hormesis, and antioxidants in neuroinflammation: role of NRLP3 in Alzheimer disease. J. Neurosci. Res. 95, $1360-1372$.

PlasticsEurope, 2020. Plastics-the Facts 2020: an Analysis of European Latest Plastics Production, Demand and Waste Data. https://www.plasticseurope.org/en.
Prokić, M.D., Radovanović, T.B., Gavrić, J.P., Faggio, C., 2019. Ecotoxicological effects of microplastics: examination of biomarkers, current state and future perspectives. Trends Anal. Chem. 111, 37-46.

Rattan, S.I.S., Fernandes, R.A., Demirovic, D., Dymek, B., Lima, C.F., 2009. Heat stress and hormetin-induced hormesis in human cells: effects on aging, wound healing, angiogenesis, and differentiation. Dose-Response 7, 90-103.

Rattan, S.I.S., Kryzch, V., Schnebert, S., Perrier, E., Nizard, C., 2013. Hormesis-based anti-aging products: a case study of a novel cosmetic. Dose-Response 11, 99-108.

Revel, M., Châtel, A., Perrein-Ettajani, H., Bruneau, M., Akcha, F., Sussarellu, R., Rouxel, J., Costil, K., Decottignies, P., Cognie, B., Lagarde, F., Mouneyrac, C., 2020. Realistic environmental exposure to microplastics does not induce biological effects in the Pacific oyster Crassostrea gigas. Mar. Pollut. Bull. 150, 110627.

Rochman, C.M., Browne, M.A., Halpern, B.S., Hentschel, B.T., Hoh, E., Karapanagioti, H. K., Rios-Mendoza, L.M., Takada, H., Teh, S., Thompson, R.C., 2013. Classify plastic waste as hazardous. Nature 494, 169-171.

Sahebkar, A., Kotani, K., Serban, C., Ursoniu, S., Mikhailidis, D.P., Jones, S.R., Ray, K.K., Blaha, M.J., Rysz, J., Toth, P.P., Muntner, P., Lip, G.Y.H., Banach, M., 2015. Lipid and blood pressure meta-analysis collaboration (LBPMC) group. Statin therapy reduces plasma endothelin-1 concentrations: A meta-analysis of 15 randomized controlled trials. Atherosclerosis 241, 433-442.

Santoro, A., Martucci, M., Conte, M., Capri, M., Franceschi, C., Salvioli, S., 2020. Inflammaging, hormesis and the rationale for anti-aging strategies. Ageing Res. Rev. 64, 101142.

Santos, D., Luzio, A., Matos, C., Bellas, J., Monteiro, S.M., Félix, L., 2021. Microplastics alone or co-exposed with copper induce neurotoxicity and behavioral alterations on zebrafish larvae after a subchronic exposure. Aquat. Toxicol., 105814

Setälä, O., Fleming-Lehtinen, V., Lehtiniemi, M., 2014. Ingestion and transfer of microplastics in the planktonic food web. Environ. Pollut. 185, 77-83.

Shibamoto, Y., Nakamura, H., 2018. Overview of biological, epidemiological, and clinical evidence of radiation hormesis. Int. J. Mol. Sci. 19, 2387.

Song, Y.K., Hong, S.H., Jang, M., Kang, J.H., Kwon, O.Y., Han, G.M., Shim, W.J., 2014. Large accumulation of micro-sized synthetic polymer particles in the sea surface microlayer. Environ. Sci. Technol. 48, 9014-9021.

Strady, E., Kieu-Le, T.C., Gasperi, J., Tassin, B., 2020. Temporal dynamic of anthropogenic fibers in a tropical river-estuarine system. Environ. Pollut. 259, 113897.

Sun, H., Calabrese, E.J., Lin, Z., Lian, B., Zhang, X., 2020. Similarities between the Yin/ Yang doctrine and hormesis in toxicology and pharmacology. Trends Pharmacol. Sci. 41, 544-556.

Sun, X., Chen, B., Li, Q., Liu, N., Xia, B., Zhu, L., Qu, K., 2018. Toxicities of polystyrene nano- and microplastics toward marine bacterium Halomonas alkaliphile. Sci. Total Environ. 642, 1378-1385.

Teng, J., Zhao, J., Zhu, X., Shan, E., Zhang, C., Zhang, W., Wang, Q., 2021. Toxic effects of exposure to microplastics with environmentally relevant shapes and concentrations: accumulation, energy metabolism and tissue damage in oyster Crassostrea gigas. Environ. Pollut. 269, 116169.

Thompson, R.C., 2015. Microplastics in the marine environment: sources, consequences and solutions. In: Bergmann, M., Gutow, L., Klages, M. (Eds.), Marine Anthropogenic Litter. Springer, Berlin, pp. 185-200.

Trestrail, C., Nugegoda, D., Shimeta, J., 2020. Invertebrate responses to microplastic ingestion: reviewing the role of the antioxidant system. Sci. Total Environ. 734, 138559.

Trucco, E., Tolosana, J.M., Arbelo, E., Doltra, A., Castel, M.Á., Benito, E., Borràs, R., Guasch, E., Vidorreta, S., Vidal, B., Montserrat, S., Sitges, M., Berruezo, A., Brugada, J., Mont, L., 2018. Improvement of reverse remodeling using electrocardiogram fusion-optimized intervals in cardiac resynchronization therapy: a randomized study. JACC Clin. Electrophysiol. 4, 181-189.

Vandenberg, L.N., 2014. Non-monotonic dose responses in studies of endocrine disrupting chemicals: bisphenol a as a case study. Dose-Response 12, 259-276.

Viebahn-Hänsler, R., Fernández, O.S.L., Fahmy, Z., 2012. Ozone in medicine: the lowdose ozone concept-guidelines and treatment strategies. Ozone Sci. Eng. 34, 408-424.

Wang, F., Wong, C.S., Chen, D., Lu, X., Wang, F., Zeng, E.Y., 2018. Interaction of toxic chemicals with microplastics: a critical review. Water Res. 139, 208-219.

Wiesenack, C., Fiegl, C., Keyser, A., Laule, S., Prasser, C., Keyl, C., 2005. Continuously assessed right ventricular end-diastolic volume as a marker of cardiac preload and fluid responsiveness in mechanically ventilated cardiac surgical patients. Crit. Care 9, R226-R233.

Woods, M.N., Hong, T.J., Baughman, D., Andrews, G., Fields, D.M., Matrai, P.A., 2020. Accumulation and effects of microplastic fibers in American lobster larvae (Homarus americanus). Mar. Pollut. Bull. 157, 111280.

Wright, S.L., Thompson, R.C., Galloway, T.S., 2013. The physical impacts of microplastics on marine organisms: a review. Environ. Pollut. 178, 483-492.

Yang, X., Chen, J., Shen, Y., Dong, F., Chen, J., 2020. Global negative effects of livestock grazing on arbuscular mycorrhizas: a meta-analysis. Sci. Total Environ. 708, 134553.

Yu, P., Liu, Z., Wu, D., Chen, M., Lv, W., Zhao, Y., 2018. Accumulation of polystyrene microplastics in juvenile Eriocheir sinensis and oxidative stress effects in the liver. Aquat. Toxicol. 200, 28-36.

Yu, S.P., Chan, B.K.K., 2020. Intergenerational microplastics impact the intertidal barnacle Amphibalanus amphitrite during the planktonic larval and benthic adult stages. Environ. Pollut. 267, 115560.

Yu, S.P., Cole, M., Chan, B.K.K., 2020. Review: effects of microplastic on zooplankton survival and sublethal responsesnull. In: Hawkins, S.J., Allcock, A.L., Bates, A.E., Evans, A.J., Firth, L.B., McQuaid, C.D., Russell, B.D., Smith, I.P., Swearer, S.E., 
Todd, P.A. (Eds.), Oceanography and Marine Biology: an Annual Review, vol. 58. CRC Press, Taylor \& Francis Group, pp. 351-394.

Zhang, Z., Ju, Z., Wells, M.C., Walter, R.B., 2009. Genomic approaches in the

identification of hypoxia biomarkers in model fish species. J. Exp. Mar. Biol. Ecol. 381, S180-S187.
Ziajahromi, S., Kumar, A., Neale, P.A., Leusch, F.D.L., 2017. Impact of microplastic beads and fibers on waterflea (Ceriodaphnia dubia) survival, growth, and reproduction: implications of single and mixture exposures. Environ. Sci. Technol. 51, 13397-13406. 